\title{
VIII
}

\section{A Tubal Mole Removed during the Process of Abortion.}

\author{
By Alban Doran, F.R.C.S., \\ Surgeon to the Samaritan Free Hospital, London.
}

IN the case which I am about to relate, the appearances of the parts removed by operation plainly indicated tubal abortion. On the other hand, the clinical features of the case were by no means typical. I think, therefore, that this example of tubal abortion in progress, when revealed by an abdominal section, is worth recording. As diagnosis was not easy, I will further make some mention of two other cases of acute pelvic disease under my care at the same time, where also the symptoms were not highly characteristic, and where operative interference showed that there was no tubal gestation.

F.D., aged 34, married 14 years, came under the care of Dr. Cuthbert Lockyer in the out-patient department of the Samaritan Hospital at the end of last May. She complained of abdominal pains coming on and passing off for some time. For two months there had been a slight "show" of blood almost daily. The patient definitely stated that just four weeks before she applied at the hospital she had had an attack of violent pain referred to the lumbo-sacral region, followed by difficult and painful micturition. On May 27th very severe pains set in and she went to bed; then almost immediately a great deal of green, watery discharge escaped. The pains at once ceased.

The patient was sent in to my wards on June lst. I found that she had borne but one child, now thirteen years of age; its birth occurred a year after her marriage. She had never aborted. Twelve years before admission she contracted gonorrhcea and was ill on and off for over six years; then she entered the Hospital for Women, Soho Square. Dr. Ernest Travers, Registrar, kindly looked up the notes on her case, which he copied for me :-

"Admitted October 19th, 1901, under Dr. Bedford Fenwick. Complained of pain in right side on standing, with vaginal discharge worse at menstrual periods. October 28th: Cervix dilated. Uterus curetted. Iodoform phenol applied."

This treatment proved satisfactory. For the last two years the patient continued in fair health, until the present illness began, rather abruptly, two months before admission.

The patient was well nourished, and quite free from the ex- 
pression of pain often seen in cases of chronic inflammatory disease of the uterine appendages. The mammæ were somewhat flaccid. I found that no milk could be pressed out of the nipples and noted the fact in my case book, yet the breasts were found to contain milk on the ninth day after operation.

On examination I detected a tender, fixed mass in Douglas's pouch : it did not rise above the pelvic brim, and did not pulsate. The cervix lay almost in its normal position, though pushed a little forwards. The sound passed two inches and a half forwards, the uterus moved independently of the mass, which was quite fixed.

The temperature on admission reached $100^{\circ}$, and remained at about $99^{\circ}$ from the second day until a week later; the pulse was 72 , small and regular. The patient had suffered from scarlet fever when a child, but had never been subject to any bad illness excepting the pelvic disorder already noted. She complained, however, of habitual constipation. The tongue was moist, indented, covered with patchy fur and tremulous. The urine on the day after admission was distinctly albuminous, golden yellow, clear, and very acid--8.g., 1,022. By the next day the albumen had disappeared and none was detected during convalescence.

On June 7 th $I$ operated with the assistance of Dr. J. Abernethy Willett, Mr. Cecil Hughes administering the anæsthetic. The pelvis was elevated. The abdominal parietes bled very smartly when incised, but there was not a drop of blood free in the peritoneal cavity, and there were no adhesions above the pelvic brim.

On inspecting the pelvis, I found the body of the uterus distinctly enlarged, with the appendages and some coils of intestine adherent to its posterior surface. The left appendages were bound down by soft adhesions, but they appeared healthy; the Fallopian tube was unobstructed. I set them free and did not remove them. They had been pushed upwards by the mass in Douglas's pouch. That mass was the right tube greatly distended. It adhered to the cæcum, the back of the uterus and the rectum, but the adhesions were very recent and easily broken down. I found, therefore, no difficulty in drawing up the tubal sac and removing it with the ovary. I saw, when amputating the sac, that a mass of clot projected from the ostium. The clot was quite dry, and there was not a trace of free blood or any other fluid in the pelvic cavity. All the viscera in that cavity were adherent, so that there was no free space for blood.

On June 16th the patient complained of tenderness and swelling of the breasts; they were found to be full of milk. On July 5th she was discharged, in very good health. The patient wrote to me in September, saying that menstruation had occurred in the second week of July, August, and September with perfect regularity. 
Fig. 1.

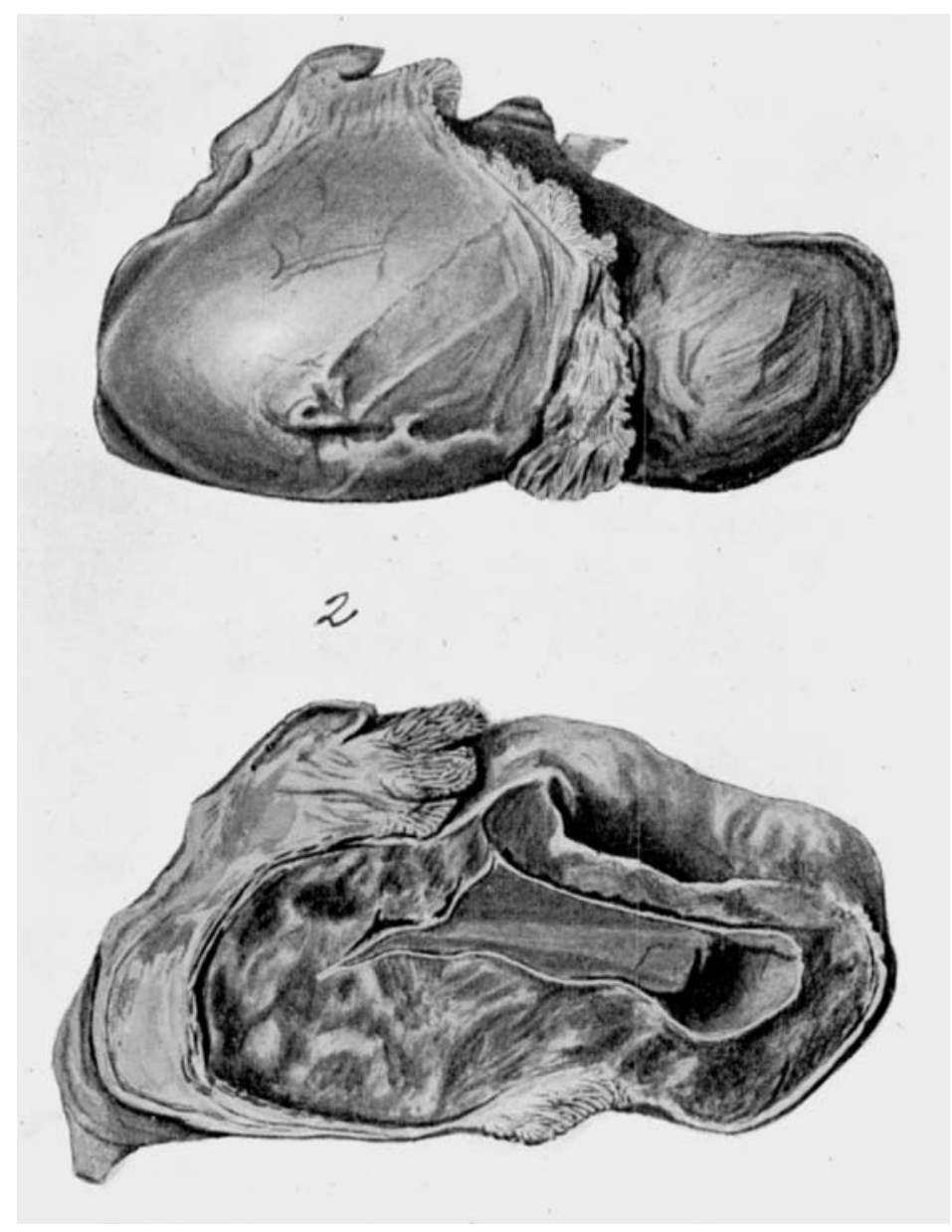

Fig. :2. 
3

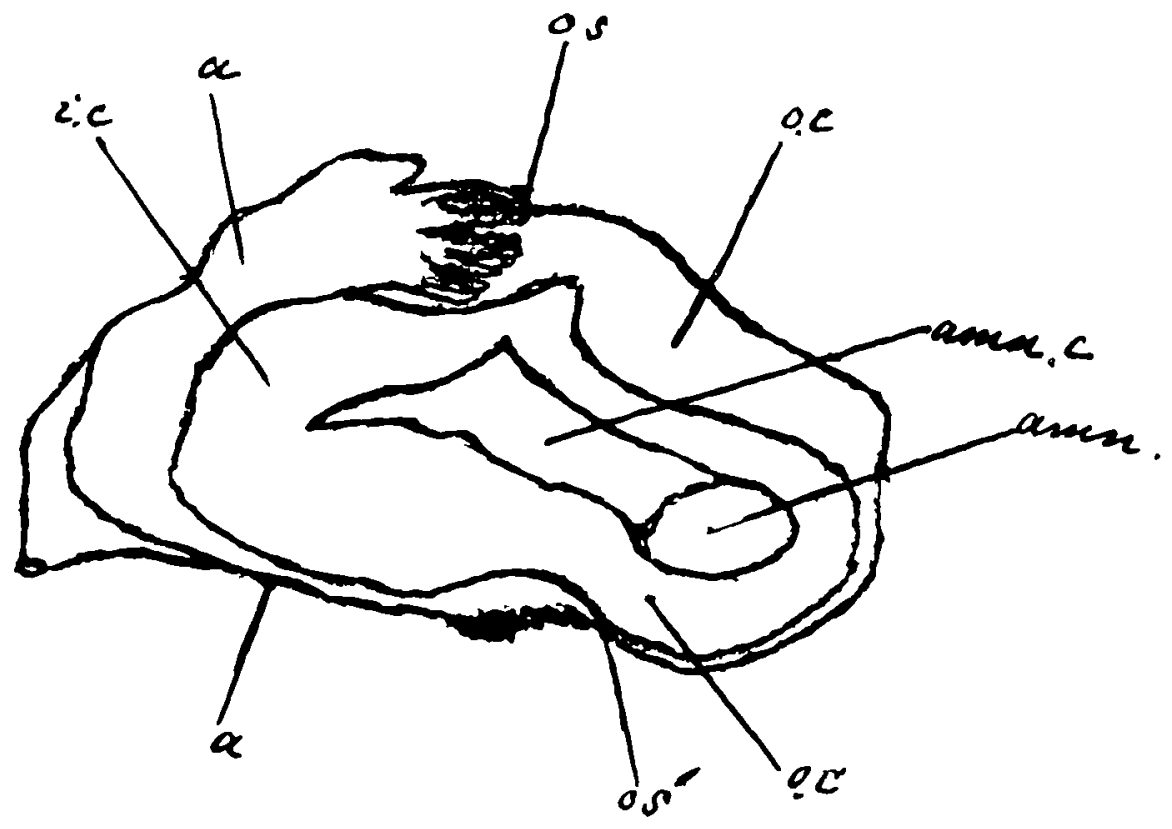

Fig. ": 
Description of the Specimen. On July 7th the tubal sac was sent to the museum of the Royal College of Surgeons. Mr. Shattock immersed it at once in Kaiserling's solution, and on July 13th he divided it vertically into two equal parts.

The length of the amputated tube and protruding clot was $4 \frac{1}{2}$ inches; the clot projected an inch and a half beyond the ostium. The circumference of the ostium was $5 \frac{1}{8}$ inches, its diameter $1 \frac{1}{4}$ inch. The circumference of the clot, at its widest portion half an inch beyond the ostium, was $4 \frac{3}{4}$ inches.

The specimen consisted of the tube with its infundibular portion distended and extremely dilated at the ostium, from which the clot protruded. The tubal wall was of a livid bluish-grey colour with dilated vessels. Fig. I. represents the external appearances of the specimen. The fimbriæ are seen clearly and are very prominent below, the gape of the ostium is seen to be wide, the upper portion of the ostium appears retracted. The specimen suggests active contraction of the tube, a subject which has given rise to much controversy. A summary of recent opinions on the share which the Fallopian tube takes in the expulsion of the ovum will be found in Dr. Russell Andrews' Critical Review in this Journal, vol. ix. (June, 1906), p. 468. In von Strauch's case the ovum was half extruded from the ostium, and was held by a broad placental pedicle to the tube high up in its canal. Outside the tube was a deep depression corresponding to the attachment of the pedicle. This depression, von Strauch contends, could only have been produced by contraction of the tube to expel its contents.

In my own case, however, there is no positive evidence that the tubal mole was expelled mainly by contractions of the tubal walls. These walls were certainly thickened, as seen in the section, but the thickening did not represent pure muscular hypertrophy.*

On inspecting the cut surface of the longitudinally divided sac (Fig. II.), the walls of the Fallopian tube (Fig. III. (a)) appeared much thickened, its canal was filled by the inner part of the clot $(i . c)$ which projected from the dilated ostium $\left(o s, o s^{1}\right)$. The entire length of the clot was exactly 3 inches. Its inner portion appeared fairly uniform, whilst in the outer portion (o.c) lay an oval cavity (amn) half an inch in its long (almost vertical) diameter, lined with a semi-transparent, smooth membrane, bearing all the appearances of an amniotic cavity, but I failed to find any relics of an embryo.

* This question was discussed when I exhibited, at a meeting of the Obstetrical Society of London, a fine specimen of tubal mole, with the fæetus well preserved, now in the Museum of the Royal College of Surgeons (Pathol. Ser., No. 4695L). Dr. Cullingworth doubted Von Strauch's conclusions, and showed that the spasmodic pains so frequent in tubal pregnancy may be due to uterine, not tubal, contractions (Trans. Obst. Soc., vol. xlii., pp. 134-9). 
The cavity seemed to be prolonged inwards, as a channel in the clot, over an inch in length and three-eighths of an inch at its widest part tailing off into a kind of process in the portion of the clot which lay within the canal of the Fallopian tube. This channel was evidently part of the amniotic cavity. It contained coagulum (amn. c.) in part decolourised, but more recent and less organized than the main clot in which the amniotic cavity was situated.

Sections were made through the clot around the amniotic cavity. When they were examined under the microscope, numerous wellformed chorionic villi were detected.

Differential Diagnosis. Dr. Haultain has dwelt upon difficulties of diagnosis. ${ }^{*}$ It happened that when the present case was under my care at the Samaritan Hospital I had two other instructive examples of acute pelvic disease in my wards.

(1) Mrs. J., aged 22; no children, one miscarriage at the fifth month, five and a half years ago; pelvic pains ever since. Recently, dyspareunia, dysuria, sharp attacles of hypogastric pain. Period every three weeks, quite regular. Irregular hamorrhages, blood dark, for fourteen days before operation, when under my own observation. I detected a tender, convex body in the right fornix displacing the cervix to the left. Uterus almost fixed. Breasts large; five days before operation a little thick white fluid could be pressed out of the nipples. Areolæ very dark (patient dark complexioned), but edges sharply defined. Temperature reached $100^{\circ}$ on three occasions within a fortnight of the operation. At the operation the parietes did not bleed freely. I removed a large pyosalpinx with the adjacent right ovary. Left appendages bound down by soft adhesions, otherwise normal. Uterus not gravid. The dysuria disappeared during convalescence.

The presence of a thick white fluid in the breasts was remarkable. The uterus was small and firm, and certainly not gravid. The patient declared that she had not been pregnant for over five years, and the extensive inflammatory changes in the appendages almost precluded recent pregnancy.

(2) Mrs. R., aged 21; married six months. Seven weeks before operation miscarried at about second month; bled for a week. Fourteen days later, fœetid discharge followed by pains in iliac fossæ. Violent attack of pain on the night before admission. Period regular and scanty, but not seen again since the abortion. I detected a mass in the right iliac fossa reaching downwards into right fornix. A smaller mass in the left fornix. Cervix displaced towards left and almost fixed. Powdery dark blood issued from uterus. Breasts

* "A Clinical Experience of Ectopic Pregnancy," Journal of Obst. and Gyn. of Brit. Emp., June 1906, p. 403 . Several interesting cases sinulating tubal gestation will be found at pp. $407-8$. 
small, areolæ virgin type. Temperature $99^{\circ}$ four hours before operation. At the operation the parietes bled but little. I removed two large pelvic tumours, double tubo-ovarian abscess; they have been carefully examined and preserved by Dr. Cutbbert Lockyer. He found no trace of tubercle or of ectopic gestation. The uterus was free from placental relics, but there was much "show" for two days after the operation. It then disappeared and there was no more discharge of any kind during convalescence.

This case did not present much difficulty in diagnosis; inflammatory disease of the appendages was evident, and it was probably older than the abortion. The powdery dark blood, "Cullingworth's symptom," however, made me suspect abnormal gestation. Haultain dwells on the confusion of abortion in uterine pregnancy with early ectopic pregnancy. In this case the patient was attended, when she miscarried, not by any doctor or even by a midwife, but by an old woman who lived in the same house, and the patient never saw what was expelled from the uterus. The history of foetid discharge during convalescence indicated uterine abortion and temporary retention of membranes with septic infection of tubes already diseased and consequent complications of a grave nature detected at the operation. In fact, as I have already observed, diagnosis was not difficult, but the slight obscurity about the abortion and the discharge of powdery dark blood suggested the probability of tubal gestation.

Bearing these three examples of acute pelvic disease in mind, I will now consider some of the symptoms noted in the case of tubal abortion :-

(1) Long interval since last pregnancy.

(2) History of previous inflammation.

(3) Absence of free blood in peritoneal cavity.

(4) Vascularity of abdominal walls.

(5) Rise of temperature and " ostial trickle."

(6) Constant "show" of blood masking amenorrhœa.

(7) Absence of pulsation in fornices.

(8) Sudden discharge of green matter.

(1) The long interval since the previous pregnancy favoured the diagnosis of tubal gestation; but Parry, who pointed out its frequency over thirty years ago, was aware that the interval is in many cases quite short, and experience has supported the conclusions of this great pioneer of the now bulky literature of ectopic gestation.

(2) The history of previous pelvic inflammation was of no assistance in diagnosis. Its relation to tubal pregnancy is uncertain, and Couvelaire, in his splendid monograph, Etudes Anatomiques sur les Grossesses Tubaires (1901), shows that tubal inflammation is 
not essential to the development of the pregnancy, and is in many cases a result, not a cause. A remarkable symptom in this case, the sudden escape of green, watery discharge, will be considered presently.

(3) There was no free blood in the peritoneal cavity. Absence of intra-peritoneal hæmorrhage was noted in Dr. Galabin's curious case of complete tubal abortion produced by bimanual examination, ${ }^{1}$ but the expelled mole was much smaller than in my specimen. It was otherwise in two well-known reports of operation during the process of abortion, cases homologous to my own and at about the same stage of pregnancy. In Bland-Sutton's patient "fluid venous blood inundated the belly" and the pelvis was filled with coagula. ${ }^{2}$ In John Phillips's case "about half a pint of dark fluid blood and several black clots" were found in the peritoneal cavity. ${ }^{3}$ In the present instance there were soft adhesions, doubtless a check to hæmorrhage; they would most likely have proved inefficient had the mole been completely extruded. Still, in that event, the hæmorrhage might have ceased, the tube regaining its normal condition. I have discussed elsewhere ${ }^{4}$ my own experience of these hæmorrhages and the opinions of Taylor, Champneys and others on operative and conservative treatment of tubal pregnancy.

(4) I noted that the abdominal parietes bled very smartly when incised. This symptom, as I may term it, is usually observed in association with any form of pregnancy ${ }^{5}$ in this instance, let it be noted, gestation had already been checked when the abdominal wall was incised. In the case of tubo-ovarian abscess there was hardly any hæmorrhage when the wound was made, although the patient was young. It is true that she was anæmic and ill-nourished, but in the case of pyosalpinx there was also very little hæmorrhage from the abdominal wound, yet the patient was young and robust and the recti were well-developed.

(5) The high temperature following the attack of pain in the lower part of the abdomen on May $27 \mathrm{th}$ is instructive in relation to tubal abortion. Dr. Haultain observes that "the physical signs which develop from the ostial trickle consist in sudden severe hypogastric pain, particularly referable to the side, marked tenderness of the abdomen and an increased temperature." $\mathrm{My}$ experience

1 "Tubal Abcrtion produced by Bimanual Examination," Trans. Obstet. Society of London, vol. xlvii., p. 332.

2 "On a Case of Tubal Abortion in which the 'Mole' was in process of Extrusion at the Time of Operation." Ibid., vol. xlii., p. 311.

3 "A Case of Tubal Mole; Operation during the Process of Abortion," Journal of Obst. and Gyn. of Brit. Emp., June 1906, p. 443.

4 "Hæmatoma and Hrematocele : a Study of Two Cases of Early Tubal Pregnancy," Trans. Obst. Soc., Lond., vol. xliv., p. 213.

5 It is often so well-marked in patients with uterine fibroid as to be almost diagnostic in doubtful cases where the tumour is partly cystic. 
agrees with Dr. Haultain's, the rise of temperature was in this case associated with a very limited "trickle." It was also distinct in a case of tubal mole," where the ostium was open and a little fluid blood came in contact with the adjacent peritoneum. In other instances where much blood "trickled" away, I have found marked rise of temperature with no evidence of sepsis.

(6) There had been a slight "show" of blood almost daily for two months before the operation. I may be allowed to term this symptom "masked amenorrhœa." Irregular bleedings are exceedingly common in the early stages of tubal gestation and are often mistaken by the patient for catamenial periods, but continuous "show" is, in my experience, less frequent. Hæmorrhages, however, occurred in the two other cases under my observation at the same time, though there was no tubal gestation in either instance, a fact on which I have already made some comment.

(7) There was no pulsation in the right fornix, or in Douglas's pouch. Yet I have noted this symptom very distinctly in a case of hæmatocele and also in an instance of true hæmatoma, continuing after the pregnancy had been interrupted. ${ }^{2}$ It was absent in the two cases of diseased non-gravid tubes reported in this communication.

(8) The green, watery discharge, following an acute attack of pain, was the most confusing symptom in this case of tubal abortion. The patient dwelt on the fact that she had contracted gonorrhœa twelve years before, and I was able to obtuin a trustworthy record of pelvic disease which came on a few years later. Hence, notwithstanding the clear history of recent acute pelvic pain, I could not diagnose tubal gestation with certainty. The tender mass in Douglas's pouch suggested the possibility of pyosalpinx. No decidua was detected; perhaps it had come away with the discharge.

Dysuria was a distinct feature in this case, but was just as marked in the patient from whom I removed a large pyosalpinx.

In conclusion, I need only dwell on one subject in regard to the operation performed in this case of tubal abortion. Finding the opposite appendages healthy I saved them. I do not approve of removal of normal appendages, still less of hysterectomy, in operations for tubal pregnancy in its early stages. In four cases of this class where I removed the tubal sac and saved the opposite appendages, the patient afterwards had a normal uterine pregnancy. Three of these cases have already been recorded in this JodRnaL. ${ }^{3}$

1 The case mentioned above, Museum Royal College of Surgeons, No. 4695L.

2 Loc. jam cit, pp. 211 and 216.

3 "A Case of Repeated Tubal Pregnancy," vol. vii., p. 403.

Fig. I. External appearance of the tubal sac expelling the mole.

Fig. Ir. The sac seen in section.

FIG. III. Diagrammatic sketch taken from Fig. ii. : $a, a$, tubal walls, greatly thickened; os. os, ${ }^{1}$ ostium of tube; i.c, portion of the clot within tubal canal; o.c, portion outside canal; amn, amniotic cavity; amn.c, clot partly occupying the cavity (see text). 